\title{
Preventive Cold Acclimation Augments the Reparative Function of Endothelial Progenitor Cells in Mice
}

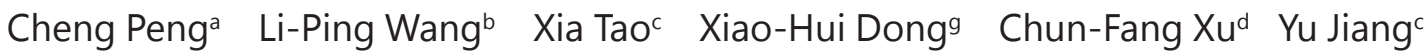 \\ Chun-Long Liu ${ }^{d}$ Hui-Fang Ma ${ }^{a}$ Chuan Zhang ${ }^{d}$ Alex F Chen ${ }^{f}$ He-Hui Xiea,e,f \\ aSchool of Public Health and Hongqiao International Institute of Medicine, Shanghai Jiao Tong \\ University School of Medicine, Shanghai, 'bepartment of Pharmacy, Zhongshan Hospital, Qingpu \\ branch, Fudan University, Shanghai, 'Department of Pharmacy, Shanghai Changzheng Hospital, The \\ Second Military Medical University, Shanghai, ${ }^{d}$ Department of Identification of Traditional Chinese \\ Medicine, The Second Military Medical University, Shanghai, eMOE-Shanghai Key Laboratory of \\ Children's Environmental Health, Xinhua Hospital, Shanghai Jiao Tong University School of Medicine, \\ Shanghai, ${ }^{\top}$ Third Xiangya Hospital and the Institute of Vascular Disease and Translational Medicine, \\ Central South University, Changsha, Hunan, 9Department of Pharmacy, Shanghai East Hospital, Tongji \\ University School of Medicine, Shanghai, China
}

\section{Key Words}

Stroke $\bullet$ Cold acclimation $\bullet$ Endothelial progenitor cell $•$ Angiogenesis

\begin{abstract}
Background/Aims: Chronic cold exposure may increase energy expenditure and contribute to counteracting obesity, an important risk factor for cerebrocardiovascular diseases. This study sought to evaluate whether preventive cold acclimation before ischemia onset might be a promising option for preventing cerebral ischemic injury. Methods: After a 14-day cold acclimation period, young and aged mice were subjected to permanent cerebral ischemia, and histological analyses and behavioral tests were performed. Mouse endothelial progenitor cells (EPCs) were isolated, their function and number were determined, and the effects of EPC transplantation on cerebral ischemic injury were investigated. Results: Preventive cold acclimation before ischemia onset increased EPC function, promoted ischemic brain angiogenesis, protected against cerebral ischemic injury, and improved long-term stroke outcomes in young mice. In addition, transplanted EPCs from cold-exposed mice had a greater ability to reduce cerebral ischemic injury and promote local angiogenesis compared to those from control mice, and EPCs from donor animals could integrate into the recipient ischemic murine brain. Furthermore, transplanted EPCs might exert paracrine effects on cerebral ischemic injury, which could be improved by preventive cold acclimation. Moreover, preventive cold acclimation could also enhance EPC function, promote local angiogenesis, and protect against cerebral ischemic injury in aged mice. Conclusions: Preventive cold acclimation before ischemia onset improved long-term stroke outcomes in mice at least in part via promoting the reparative function of EPC. Our findings imply that a variable indoor environment with frequent cold exposure might benefit individuals at high risk for stroke.
\end{abstract}

C. Peng and L. Wang contributed equally to this work. 


\section{Cellular Physiology Cell Physiol Biochem 2018:45:175-191 \begin{tabular}{l|l|l}
\hline DOI: 10.1159/000486356 & $\begin{array}{l}\text { C) 2018 The Author(s). Published by S. Karger AG, Basel } \\
\text { www.karger.com/cpb }\end{array}$
\end{tabular}}

Peng et al.: Cold Acclimation, EPCs and Stroke

\section{Introduction}

Cold acclimation is the most powerful and physiological stimulus for brown adipose tissue (BAT) activation in both small rodents and humans $[1,2]$. BAT burns fat to produce heat when the body is exposed to cold and plays a role in energy metabolism. Chronic cold exposure can recruit BAT, increase energy expenditure, and thereby contribute to body fat reduction in humans $[1,2]$. Moreover, energy metabolism disorders (e.g., obesity, diabetes) are associated with the impairment of endothelial progenitor cells (EPCs) and EPC-mediated ischemic angiogenesis; thus, they are important risk factors of cardiovascular and cerebrovascular diseases including stroke [3-5]. EPCs, a circulating bone marrow (BM)derived cell population that participates in vasculogenesis and vascular homeostasis, have been used to successfully improve functional recovery of ischemic organs (including the brain) after ischemic injury [4-6]. Thus, it can be logically speculated that preventive cold acclimation before ischemia onset might promote EPC function and EPC-mediated ischemic angiogenesis by improving energy metabolism, thereby serving as a potential strategy to prevent ischemic diseases such as ischemic stroke, myocardial infarction, and limbic ischemic injury.

Ischemic stroke is a devastating disease, and the major cause of mortality and morbidity worldwide [7-9]. Nowadays, urgent reperfusion of the ischemic brain using thrombolytic drug tissue plasminogen activator (tPA) is the first target of stroke treatment, but approximately $3 \%$ of the population suffering an ischemic stroke benefit from tPA, largely due to the drug's short therapeutic window $[8,9]$. Thus, effective prevention remains the best approach to reducing stroke burden [9]. Despite the use of various risk-reduction measures, such as the use of antihypertensives or platelet anti-aggregants, for primary and secondary stroke prevention, stroke remains a major healthcare problem [9]. Accordingly, developing potential new strategies targeting stroke prevention should be of great clinical importance.

Therapeutic hypothermia after ischemia onset may be a neuroprotectant against experimental cerebral ischemia [10]. Considering the aforementioned findings, this study sought to test the hypothesis that preventive cold acclimation before ischemia onset may be a promising and economic option for preventing cerebral ischemic injury by promoting the reparative function of EPCs.

\section{Materials and Methods}

\section{Animals}

Young male C57BL/6 mice (10-12 weeks of age, 20-25 g each) were purchased from Sino-British SIPPR/BK Lab Animal Ltd. (Shanghai, China). Male aged mice (52-55 weeks of age, 35-40 g each) were provided by the Animal Center of the Second Military Medical University (Shanghai, China). Male C57BL/6Tg (CAG-EGFP) green fluorescent protein (GFP) transgenic mice (10-12 weeks of age) were purchased from Shanghai Model Organisms Center, Inc. (Shanghai, China). The animals were housed at a controlled temperature $\left(22-24^{\circ} \mathrm{C}\right)$ and lighting (8:00-20:00 light, 20:00-8:00 dark) with free access to food and tap water. All animals received humane care, and the experimental procedures were performed in compliance with the institutional animal care guidelines. All the experiments were performed in a random and blinded fashion.

\section{Preventive Cold Acclimation before Ischemia Onset in Young Mice}

Young male C57BL/6 mice (10-12 weeks of age, 20-25 g each) were randomly divided into two groups: mice in the first group were exposed to an environmental temperature of $16^{\circ} \mathrm{C}$ for 14 consecutive days $(2$ hours on the first day, 4 hours on the second day, and 6 hours on each remaining day) (cold group); mice in the other group maintained their usual lifestyle $\left(22-24^{\circ} \mathrm{C}\right)$ without cold exposure during the same period (control group) [2]. The mice were then used for EPC isolation and assessment (Fig. 1A) or were subjected to permanent focal cerebral ischemia (Fig. 2A and 3A). 


\section{Cellular Physiology Cell Physiol Biochem 2018:45:175-191 \begin{tabular}{ll|l} 
and Biochemistry Published online: January 15, 2018 & $\begin{array}{l}\text { (C) } 2018 \text { The Author(s). Published by S. Karger AG, Basel } \\
\text { www.karger.com/cpb }\end{array}$
\end{tabular}}

Peng et al.: Cold Acclimation, EPCs and Stroke

\section{Quantification of Circulating EPCs in Young Mice}

After 14-day cold acclimation (Fig. 1A), the circulating EPCs in the peripheral blood ( $\mathrm{n}=16-18$ per group) were quantified by flow cytometry using a previously reported technique $[4,11,12]$. Briefly, peripheral blood was obtained by cardiac puncture after the mice were anesthetized. Peripheral blood mononuclear cells (PB-MNCs) were isolated by Histopaque-1083 (Sigma) density gradient centrifugation at $400 \times g$ for $30 \mathrm{~min}$. The mononuclear fraction was collected and washed in phosphate buffer saline (PBS) ( $\mathrm{pH}$ 7.4), red blood cells were lysed with ammonium chloride solution (Stemcell Technologies), then washed twice with PBS and once with 5\% albumin bovine serum (BSA)/PBS (PBS-A). Freshly isolated PB-MNCs were re-suspended in $100 \mu \mathrm{L}$ of 15\% PBS-A and incubated with antibodies to Sca-1-PE (BD Pharmingen) and Flk-1-FITC (BD Pharmingen) for 1 hour on ice. The isotype-specific conjugated anti-immunoglobulin G (IgG) was used as a negative control. After washing and centrifugation, the cell pellets were suspended in $300 \mu \mathrm{L}$ of $2 \%$ paraformaldehyde. Sca-1/Flk-1 double-positive cells were quantified using a BD Flow cytometer (FACScan, Becton Dickenson) $[4,11,12]$.

\section{Bone Marrow-derived EPCs (BM-EPCs) Isolation and Culture in Young Mice}

After a 14-day cold acclimation period, BM-EPCs were isolated and cultured according to a previously reported technique $[4,11,12]$. Bone marrow-derived mononuclear cells (BM-MNCs) were isolated from the murine tibia and femur, seeded in six-well cell culture plates coated with rat vitronectin $(1 \mu \mathrm{g} / \mathrm{mL}$, Sigma $)$ at a density of $5 \times 10^{6}$ cells/well, and cultured in endothelial growth medium-2 (EGM-2; Lonza). After 4 days of culture, nonadherent cells were removed and the adherent cells were further cultivated for 3 days. The cells were then used for in vitro studies (including function assays and western blot analyses) (Fig. 1A), EPC transplantation (Fig. 4A) and a paracrine effect assessment of the EPCs.

\section{In vitro Cell Function Assays}

Migration Assay. A density of 5 x $10^{4}$ cells were loaded into the upper Boyden's chamber with M199. The lower chambers were loaded with M199 supplemented with vascular endothelial growth factor (VEGF) $50 \mathrm{ng} / \mathrm{mL}$. EPCs were allowed to migrate for 24 hours and then fixed and stained with Hochest 33258 (Sigma). The number of cells on the lower side of the membrane was counted at $\times 100$ magnification, and the mean value of five different areas was determined for each sample [12-14].

Tube Formation Assay. Matrigel-Matrix (BD Biosciences) was placed in each well of a 96-well cell culture plate and $5 \times 10^{4}$ EPCs were plated in each well with EGM-2. After 18 hours of incubation, images of the tube morphology were taken and the number of tubes was counted at random under five high-power fields (magnification, $\mathrm{x} 100$ ) per sample [4,11-13].

Adhesion Assay. In adhesion assays, $1 \times 10^{4}$ cells were plated in 96-well plates coated with mouse vitronectin $1 \mu \mathrm{g} / \mathrm{mL}$. After 2 hours of incubation, non-adherent cells were washed away and adherent cells were fixed with $2 \%$ paraformaldehyde. The nuclei were stained with Hoechst $335285 \times 10^{-6} \mathrm{~mol} / \mathrm{L}$ (Molecular Probes) for $10 \mathrm{~min}$. The number of adherent cells were counted at random under five highpower fields (magnification, $\mathrm{x} 100$ ) per sample and the mean value of the four wells was determined for each sample $[4,11-13]$.

\section{Intracellular Superoxide Measurement}

Intracellular superoxide $\left(\mathrm{O}_{2}{ }^{-}\right)$levels of the EPCs were determined by flow cytometry assay using dihydroethidium (DHE) (Sigma), a membrane-permeable dye that is oxidized to ethidium bromide in the presence of $\mathrm{O}_{2}$. After 7 days of cultivation, BM-EPCs were trypsinized, resuspended in EGM-2, and then incubated with $1 \mu \mathrm{M}$ DHE (Sigma) at $37^{\circ} \mathrm{C}$ for $30 \mathrm{~min}$ in the dark. After the incubation, the cells were washed with PBS-A and fixed in 2\% paraformaldehyde. The DHE fluorescence intensity of the cells was determined by flow cytometry $[4,11]$.

\section{Western Blot Analysis}

The western blot analysis was performed as previously described [4, 11]. Briefly, the collected EPC culture medium was concentrated with an Amicon Ultra 4 centrifugal filter device with a 10, 000 molecular weight cutoff (Millipore) according to the manufacturer's recommendations. Protein concentrations were determined using a bicinchoninic acid (BCA) protein assay kit (Pierce, Thermo), and samples containing 


\section{Cellular Physiology Cell Physiol Biochem 2018:45:175-191 \begin{tabular}{l|l|l|} 
and BOI: 10.1159/000486356 & $\begin{array}{l}\text { C) } 2018 \text { The Author(s). Published by S. Karger AG, Basel } \\
\text { www.karger.com/cpb }\end{array}$ \\
\hline
\end{tabular}}

Peng et al.: Cold Acclimation, EPCs and Stroke

equal amounts of protein were subjected to $8 \%$ sodium dodecyl sulfate-polyacrylamide gel electrophoresis (SDS/PAGE). The gels were then transferred to nitrocellulose membranes and incubated with mouse antithrombospondin-1 (1:200; Abcam Inc.) monoclonal antibody. Secondary antibodies included IR Dye 800 conjugated anti-mouse IgG (1:5000; Rockland). Bands were visualized using Odyssey Imager with Odyssey 1.1 software (Li-Cor) and quantified using NIH Image J software.

EPCs were washed with cold PBS twice and then incubated in lysis buffer. A bicinchoninic acid (BCA) protein assay kit (Pierce, Thermo) was used to quantify the protein levels. Proteins of equal quantities were loaded on $8-10 \%$ SDS/PAGE gels. Subsequently, they were transferred to nitrocellulose membranes. The membranes were blocked for $0.5 \mathrm{~h}$ in $5 \%$ milk in PBS and washed three times for $5 \mathrm{~min}$ and incubated with the primary antibodies which were purified mouse anti-endothelial nitric oxide synthase (anti-eNOS; BD Transduction Labs) and mouse anti-manganese superoxide dismutase (anti-MnSOD; BD Transduction Labs) at a dilution of 1:1000 overnight. The membranes were then washed three times with PBST (containing $0.1 \%$ Tween-20) and bound antibody was detected using anti-mouse IgG secondary antibody (1:5000; eNOS and MnSOD; CST). The bands were visualized using Odyssey Imager with Odyssey 1.1 software (LiCor) and quantified using NIH Image J software.

\section{Preventive Cold Acclimation before Ischemia Onset and Animal Stroke Model in Young Mice}

After the 14-day cold acclimation period, the mice were subjected to permanent focal cerebral ischemia as previously reported $[12,15]$. The mice were anesthetized by an intraperitoneal injection of $0.1 \mathrm{~mL}$ of $3.5 \%$ chloral hydrate per $10 \mathrm{~g}$ of body weight. A skin incision was made between the ear and the orbit on the left side. The temporalis muscle was split and a burr hole was drilled the junction of the zygomatic arch and the squamous bone, through which the stem of the left middle cerebral artery (MCA) was exposed and occluded by electrocoagulation. Three days after the MCA occlusion (Fig. 2A), behavioral tests (including the Beam Test and the Body Asymmetry Test) were performed, the animals were euthanized, and the brains were stained with 2, 3,5-triphenyltetrazolium chloride (TTC) (Sigma) to determine the infarct volume, which was corrected for swelling/edema as previously reported ( $\mathrm{n}=16-17$ per group) $[6,12,15]$.

In addition, after 3 days of cerebral ischemia (Fig. 2A), the mice were euthanized and the ischemic brains were fixed by transcardial perfusion with saline, followed by perfusion and immersion in $4 \%$ paraformaldehyde before being embedded in paraffin. A series of $6-\mu \mathrm{m}$-thick sections was cut from the block. Every tenth coronal section for a total of three sections was subjected to immunohistochemical staining. Anti-CD31 (BD Biosciences) immunostaining was performed to detect angiogenesis in the ischemic brain (n $=9$ per group) $[16,17]$.

Furthermore, as shown in Fig. 3A ( $\mathrm{n}=19-20$ per group), long-term neurobehavioral outcomes and body weights of the mice were assessed after 7, 14, 21, and 28 days of cerebral ischemia [6, 12, 15]. After 28 days of cerebral ischemia, the animals were euthanized and the brains were stained with TTC to determine the cerebral atrophy volumes as previously reported [6]. Cerebral atrophy volume was calculated by subtraction of the ipsilateral hemisphere volume from the contralateral hemisphere volume.

\section{Behavioral Tests}

1) Beam Test-Beam walking across a bridge was used to assess motor coordination and balance after stroke injury. The mice were trained for 5 days before the MCA occlusion to traverse a narrow round beam ( $5 \mathrm{~mm}$ in diameter, $900 \mathrm{~mm}$ in length) to reach an enclosed escape platform. They were placed on one end of the beam and the latency to traverse the central $80 \%$ of the beam toward the enclosed escape platform at the other end was recorded. Data are expressed as mean latency to cross the beam in three trials $[6,12,15]$.

2) Body Asymmetry Test-To measure motor asymmetry, the mice were examined using the elevated body swing test as described previously $[6,12,15]$. The mice were examined for head swings while being suspended by their tails. The direction of the swing (right or left) was recorded when the mouse turned its head sideways by approximately at a $10^{\circ}$ angle to the body's midline. After each swing, each mouse was allowed to move freely in a Plexiglas box for at least 30 seconds before undergoing the next test; the trials were repeated 20 times for each animal. The frequency of the head swings toward the contralateral side was counted and normalized as follows: (number of lateral swings in 20 tests - 10)/10 x 100\%.

\section{EPC Transplantation and Animal Stroke Model in Young Mice}

To further determine whether EPC-mediated angiogenesis is involved in the protection of preventive cold acclimation against cerebral ischemic injury in mice, $1 \times 10^{6}$ bone marrow-derived EPCs in $200 \mu \mathrm{L}$ PBS 


\section{Cellular Physiology Cell Physiol Biochem 2018:45:175-191 \begin{tabular}{ll|l} 
and Biochemistry Published online: January 15, 2018 & $\begin{array}{l}\text { C } 2018 \text { The Author(s). Published by S. Karger AG, Basel } \\
\text { www.karger.com/cpb }\end{array}$ \\
\cline { 2 - 3 }
\end{tabular}}

Peng et al.: Cold Acclimation, EPCs and Stroke

from cold-exposed and control mice were systemically injected into mice through the tail vein just after cerebral ischemia, while control animals received an equal volume of vehicle (Fig. 4A) [6, 18]. At 1 and 3 days after cerebral ischemia, behavioral tests (including the Body Asymmetry Test and Beam Test) were performed, the mice were sacrificed, and the brains were stained with TTC to determine the infarct volume, which was corrected for swelling/edema as previously reported $(n=11-13$ per group) $[6,12,15]$.

In addition, after 3 days of cerebral ischemia (Fig. 4A), the mice were euthanized and the ischemic brains were fixed by transcardial perfusion with saline, followed by perfusion and immersion in $4 \%$ paraformaldehyde before being embedded in paraffin. A series of 6 - $\mu$ m-thick sections was cut from the block. Every tenth coronal section for a total of three sections was subjected to immunohistochemical staining. Anti-CD31 antibody (BD Biosciences) immunostaining was performed to detect angiogenesis in the ischemic brain ( $\mathrm{n}=6$ per group) $[16,17]$.

\section{EPC Transplantation and In vivo EPC Integration in Young Mice}

On day 5 of culture, EPCs from cold-exposed and control mice were labeled with 5-bromo-2'deoxyuridine (BrdU, Thermo Fisher Scientific) as described previously [4]. Briefly, the BrdU labeling reagent was diluted to 1:100 in EGM-2, filtered through a $0.2-\mu \mathrm{m}$ filter, and warmed to $37^{\circ} \mathrm{C} .2 \mathrm{ml}$ of BrdU/EGM-2 was added to the cells of a six-well plate, and new medium was added daily until day 7. On day 7, the wells were washed three times with PBS, followed by trypsinization to resuspend the cells. As shown in Fig. 4A, mouse EPCs $\left(1 \times 10^{6}\right.$ cells $)$ in $200 \mu \mathrm{L}$ of PBS were then transplanted into mice via the tail vein just after cerebral ischemia was induced as previously reported $[6,18]$.

After 3 days of cerebral ischemia, the mice were euthanized and the ischemic brains were fixed by transcardial perfusion with saline, followed by perfusion and immersion in $4 \%$ paraformaldehyde before being embedded in paraffin. A series of $6-\mu \mathrm{m}$-thick sections was cut from the block. Every tenth coronal section for a total of three sections was subjected to immunohistochemical staining [16, 17]. To detect the in vivo EPC integration, slides were stained with anti-CD31 antibody (BD Biosciences), followed by BrdU antibody (Santa Cruz Biotechnology Inc.) incubation. The secondary antibodies were Alexa Fluor 488 (Abcam) or Cy3 (Abcam). The nuclei were counterstained with DAPI (Cell Signaling Technology) $[4,6]$.

In addition, EPCs from GFP transgenic mice were also used for cell tracking in the ischemic brain to detect the in vivo EPC integration in mice (Fig. 5). GFP-EPCs $\left(1 \times 10^{6}\right.$ cells) in $200 \mu \mathrm{L}$ of PBS were transplanted into mice via the tail vein just after cerebral ischemia as previously reported [6, 18]. After 3 days of cerebral ischemia, the mice were euthanized and the ischemic brains were harvested. The cell nuclei were counterstained with DAPI (Cell Signaling Technology) and the GFP-EPCs were detected in the frozen ischemic brain sections [6].

Treatment of Cerebral Ischemic Injury with EPC-Conditioned Medium in Young Mice

Bone marrow-derived mononuclear cells from cold-exposed and control mice were plated on a vitronectin (Sigma-Aldrich)-coated six-well plate at $5 \times 10^{6}$ cells/well in EGM-2 at $37^{\circ} \mathrm{C}$ with $5 \% \mathrm{CO}_{2}$. After 4 days of culture, nonadherent cells were removed and fresh EGM-2 was changed daily. At day 6 of culture, growing EPCs were washed twice with endothelial basal medium-2 without growth factors and serum (EBM-2; Lonza). Then, the fresh EBM-2 (1.5 mL/well) was added to obtain conditioned media (CM) that was collected 24 hours later. $4 \mathrm{~mL}$ CM was concentrated for $40 \mathrm{~min}$ using a 10-kDa filter unit (Millipore, Ireland) for a final volume of approximately $200 \mu \mathrm{L}$. As shown in Fig. 6C ( $\mathrm{n}=10-12$ per group), the concentrated $\mathrm{CM}(200 \mu \mathrm{L})$ was injected into mice via the tail vein just after cerebral ischemia was induced. Control mice received an equal volume of vehicle (EBM-2) [4, 19]. After 24 hours of cerebral ischemia, behavioral tests (including the Body Asymmetry Test and the Beam Test) were performed and cerebral infarct volumes were determined as previously reported $[6,12,15]$.

In addition, to investigate the potential effect of cold acclimation on paracrine factors of EPCs in mice, the secreted platelet-derived growth factor (PDGF), VEGF, and hepatocyte growth factor (HGF) levels in the concentrated CM were assessed by western blot analysis [4, 11, 19] (Fig. 7A). Protein concentrations were determined using the BCA protein assay kit (Pierce, Thermo), and samples containing equal amounts of protein were loaded onto $8 \%$ SDS/PAGE. Gels were transferred to nitrocellulose membranes and incubated with rabbit anti-PDGF polyclonal antibody (Abcam Inc.), rabbit anti-VEGF polyclonal antibody (Abcam Inc.), and rabbit anti-HGF polyclonal antibody (Abcam Inc.). The secondary antibody was IR Dye 800-conjugated anti-rabbit IgG (1:2000, Rockland). The bands were visualized using Odyssey Imager with Odyssey 1.1 software (Li-Cor) and quantified using NIH Image J software. 


\section{Cellular Physiology Cell Physiol Biochem 2018:45:175-191 \begin{tabular}{l|l} 
and Biochemistry Published online: January 15, 2018 & $\begin{array}{l}\text { C } 2018 \text { The Author(s). Published by S. Karger AG, Basel } \\
\text { www.karger.com/cpb }\end{array}$ \\
\hline DOI: 10.1159/00048636
\end{tabular}}

Peng et al.: Cold Acclimation, EPCs and Stroke

\section{Preventive Cold Acclimation before Ischemia Onset and Animal Stroke Model in Aged Mice}

Next, aged mice were employed to investigate whether the effects of cold acclimation observed in young healthy mice could be reproduced in a model with stroke risk factors. Male aged mice (52-55 weeks, 35-40 g) were randomly divided into 2 groups: a group that was exposed to an environmental temperature of $16^{\circ} \mathrm{C}$ for 14 consecutive days ( 2 hours on the first day, 4 hours on the second day, and 6 hours per day on each remaining days) (cold group); and a group in which members maintained their usual lifestyles $\left(22-24^{\circ} \mathrm{C}\right.$ ) without cold exposure during the same period (control group) [2]. The mice were then used for EPC isolation and assessment (Fig. 8A, $n=8-10$ per group) $[4,11,12]$ or were subjected to permanent focal cerebral ischemia.

After the 14-day cold acclimation period (Fig. 9A), some mice were subjected to permanent focal cerebral ischemia, while behavioral tests were performed 3 days after cerebral ischemia. Then, animals were euthanized and the brains were stained with TTC to determine the infarct volume, which was corrected for swelling/edema ( $\mathrm{n}=9-10$ per group) $[6,11,12]$. In addition, after 3 days of cerebral ischemia, some mice were euthanized and the ischemic brains were fixed by transcardial perfusion with saline, followed by perfusion and immersion in 4\% paraformaldehyde before being embedded in paraffin. A series of $6-\mu \mathrm{m}$ thick sections was cut from the block. Every tenth coronal section for a total of three sections was used for the immunohistochemical staining. Anti-CD31 antibody (BD Biosciences) immunostaining was performed to detect angiogenesis in the ischemic brain ( $\mathrm{n}=12$ per group) $[16,17]$.

\section{Statistical Analysis}

Data are expressed as mean \pm SEM. The statistical significance of the difference between two groups was detected using Student's unpaired t-test. When more than two groups were compared, one-way analysis of variance followed by Tukey's post hoc analysis was used. Values of $P<0.05$ were considered statistically significant.

\section{Results}

Preventive Cold Acclimation before Ischemia Onset Increased EPC Function and Promoted Local Angiogenesis in Ischemic Brains of Young Mice

After the 14-day cold acclimation period, the circulating EPC numbers and BM-EPC functions were determined in mice (Fig. 1A). Compared with control, 14-day preventive cold exposure significantly increased the number of circulating Sca- $1^{+} /$Flk- $1^{+}$EPCs $(+58.3 \%, P<$ 0.01) (Fig. 1B) and markedly promoted BM-EPC functions (including adhesion, migration, and tube formation functions) in mice (Fig. 1C).

To investigate the potential mechanisms underlying preventive cold acclimation improving EPC functions, eNOS, MnSOD, and thrombospondin-1 (TSP-1) expressions and intracellular superoxide levels of the EPCs were examined in young mice after the 14-day cold acclimation period (Fig. 1A). We found that both eNOS and MnSOD expression levels were significantly increased $(+22 \%, P<0.05$ and $+27 \%, P<0.05$, respectively) in EPCs from preventive cold-exposed mice compared to control (Fig. 1D and 1E). In addition, intracellular $\mathrm{O}_{2}{ }^{-}$levels and TSP-1 expression levels were markedly reduced $(-15 \%, P<0.01$ and $-16 \%, P$ $<0.01$, respectively) in EPCs from preventive cold-exposed mice compared to controls (Fig. $1 \mathrm{~F}$ and $1 \mathrm{G})$.

In addition, EPCs can secret various angiogenic growth factors to promote angiogenesis $[5,6]$. Thus, local angiogenesis in the ischemic brain was assessed at 3 days after cerebral ischemia (Fig. 2A). Capillary density was significantly increased in preventive cold-exposed mice compared with controls $(+39 \%, P<0.05)$ (Fig. 2B).

These results indicate that preventive cold acclimation before ischemia onset could increase EPC numbers and function and promote local angiogenesis in the ischemic brain of mice.

Preventive Cold Acclimation before Ischemia Onset Protected against Cerebral Ischemic Injury in Young Mice

Next we sought to investigate whether the promotion of EPC functions and local angiogenesis in the ischemic brain produced by preventive cold acclimation before ischemia 


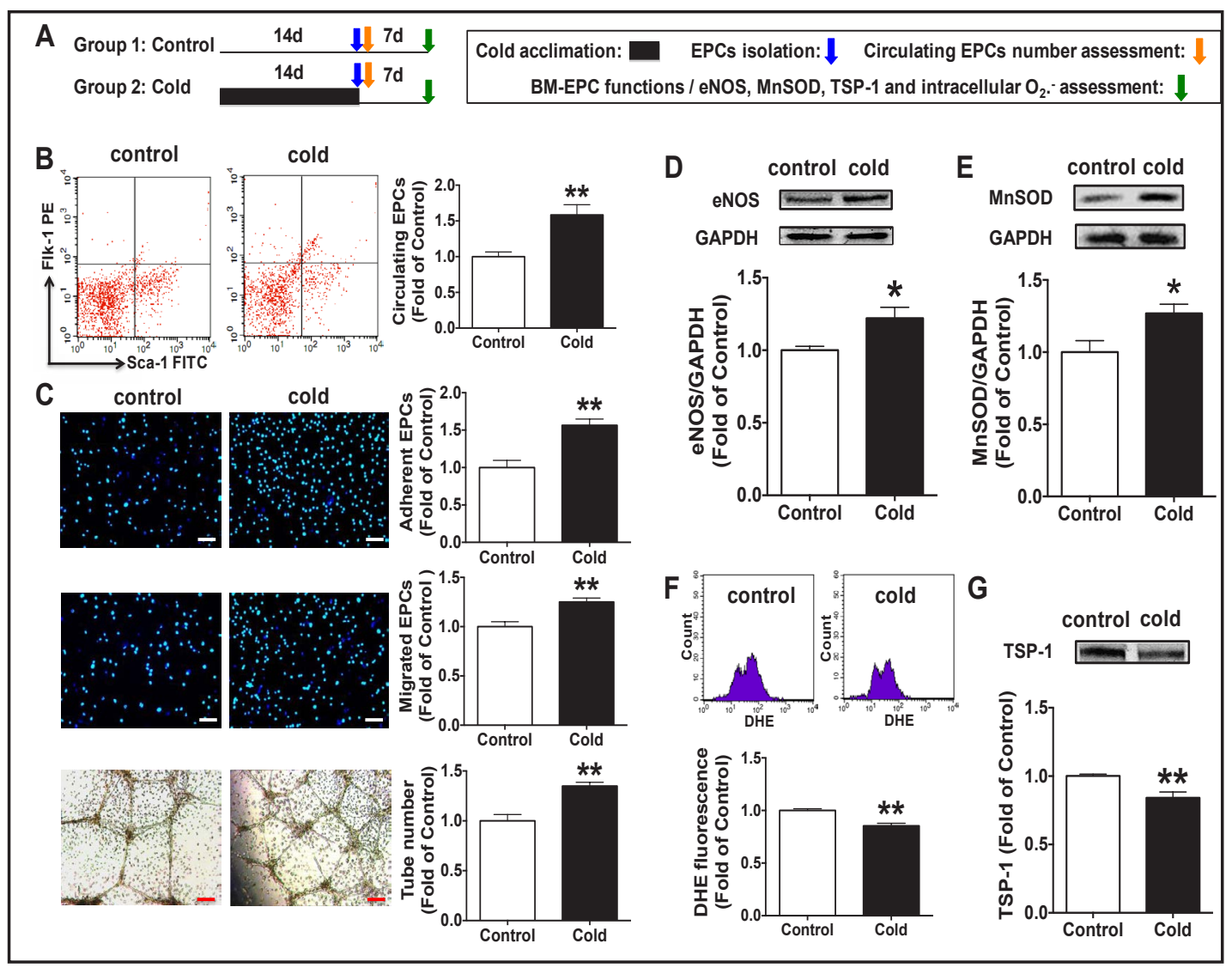

Fig. 1. Preventive cold acclimation increased circulating EPC numbers and BM-EPC functions in young mice. A. Experimental protocols: male young C57BL/6 mice (10-12 weeks) were randomly allocated to two groups. Animals were exposed to cold environment or maintained their usual lifestyle, and 14 days later, the circulating EPCs number was determined, and BM-EPCs were isolated, cultured, and examined in mice. B. The number of circulating EPCs determined by Sca-1/Flk-1 double-staining flow cytometry. $\mathrm{n}=16-18$. C. Adhesion assay, migration assay and tube formation assay of BM-EPCs. ${ }^{* *} \mathrm{P}<0.01$ vs. Control. $\mathrm{n}=8-9$. Scale bar: $100 \mu \mathrm{m}$. D. The eNOS expression levels of BM-EPCs $(n=5)$. E. The MnSOD expression levels of BM-EPCs $(\mathrm{n}=8-10)$. F. Intracellular $\mathrm{O}_{2}$ : levels of BM-EPCs $(\mathrm{n}=10)$. G. The secreted TSP-1 levels of BM-EPCs $(\mathrm{n}=$ 6-7). ${ }^{*} \mathrm{P}<0.05,{ }^{* *} \mathrm{P}<0.01$ vs. Control. Values were normalized to control. EPCs, endothelial progenitor cells; eNOS, endothelial nitric oxide synthase; TSP-1, thrombospondin-1; BM-EPCs, bone marrow-derived EPCs; Control, control mice; Cold, preventive cold-exposed mice.

onset would have a preventive action on cerebral ischemic injury in mice. After the 14-day cold acclimation period, the mice were subjected to cerebral ischemia (Fig. 2A). At 3 days after the induction of cerebral ischemia, the infarct volumes were significantly reduced $(-24 \%$, $P<0.01)$ and the corresponding neurobehavioral outcomes were markedly improved in preventive cold-exposed mice compared with controls (Fig. 2C). These results indicate that a preventive cold acclimation before ischemia onset could protect against cerebral ischemic injury in mice.

Preventive Cold Acclimation before Ischemia Onset Reduced Brain Cortex Atrophy and Improved Long-Term Neurobehavioral Outcomes after Cerebral Ischemia in Young Mice

We further evaluated the potential long-term neuroprotection of preventive cold acclimation before ischemia onset against cerebral ischemic injury (Fig. 3A) but found no significant difference in body weight between the two groups of mice (Fig. 3B). At 28 days after the induction of cerebral ischemia, the overall atrophy volume of the hemisphere was significantly reduced in preventive cold-exposed mice $(-22 \%, P<0.01)$ compared to control 
Fig. 2. Preventive cold acclimation before ischemia onset promoted angiogenesis in the ischemic brain and protected against cerebral ischemic injury in young mice. A. Surgical protocols: male young C57BL/6 mice (10-12 weeks of age) were randomly allocated to two groups. The animals were exposed to the cold environment or maintained their usual lifestyle; 14 days later, they were subjected to permanent focal cerebral ischemia. Behavioral tests were performed after 3 days of cerebral ischemia, and then the local angiogenesis in the ischemic brain and cerebral infarct volumes were determined. $\mathrm{B}$. CD31 immunostaining showing microvessels in the ischemic boundary area of the ischemic brains. The bar graph shows that the number of microvessels in the

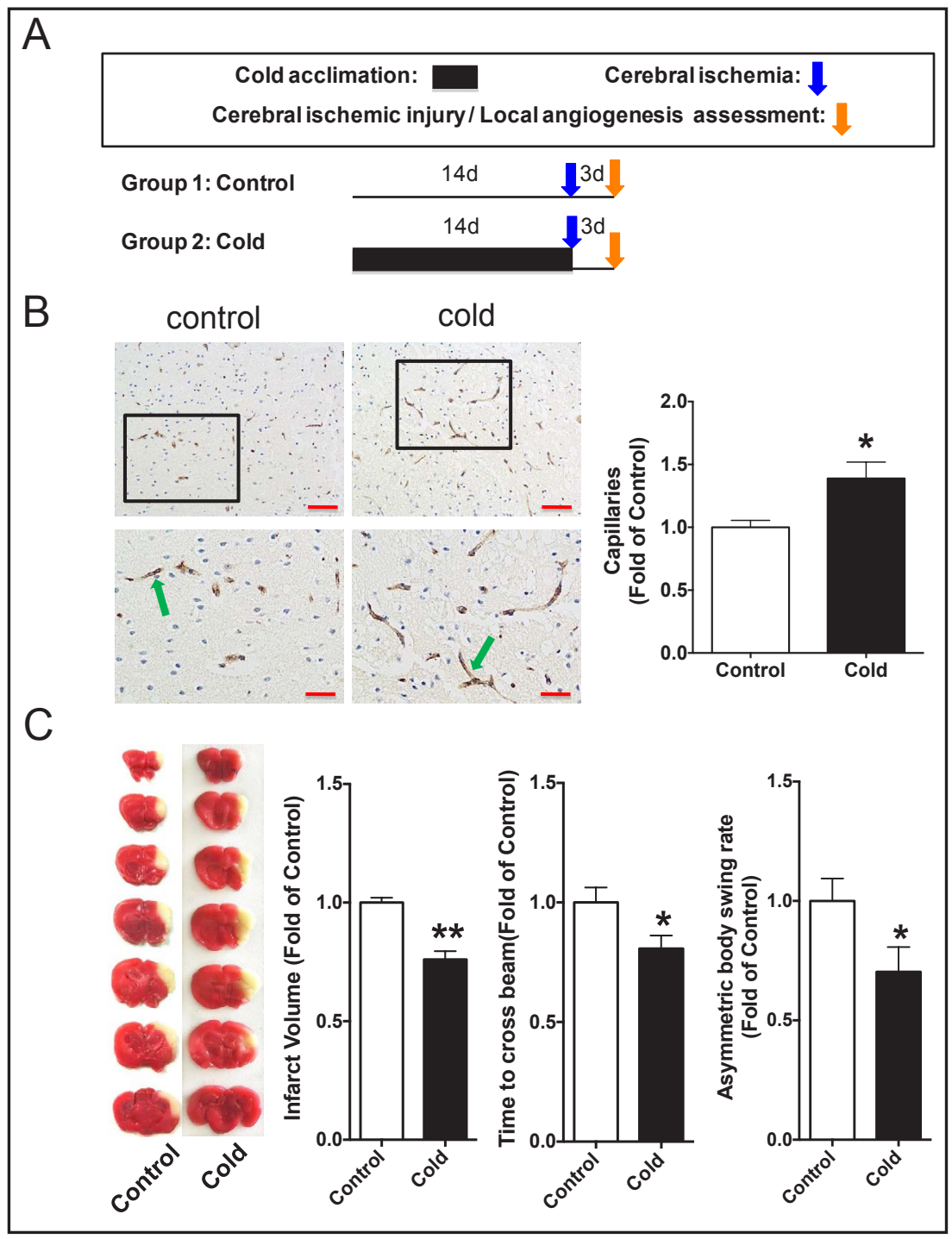
preventive cold-exposed mice was increased compared with control. Values were normalized to control. $* \mathrm{P}<0.05$ vs. Control. $\mathrm{n}=9$. Scale bar: $100 \mu \mathrm{m}$ (up); $50 \mu \mathrm{m}$ (below). C. Representative images of 2,3,5-triphenyltetrazolium chloride (TTC)-stained brain sections, cerebral infarct volumes, and neurobehavioral outcomes (including Beam Test and Body Asymmetry Test) after 3 days of cerebral ischemia. ${ }^{*} \mathrm{P}<0.05,{ }^{* *} \mathrm{P}<0.01$ vs. Control. $\mathrm{n}=16-17$. Control, control mice; Cold, preventive cold-exposed mice.

mice (Fig. 3C). We also examined the neurobehavioral outcomes at 7, 14, 21, and 28 days after cerebral ischemia was induced and found that the neurobehavioral outcomes (Beam Test and Body Asymmetry Test) were markedly improved in preventive cold-exposed mice compared with controls (Fig. 3D). These results indicate that preventive cold acclimation before ischemia onset could improve long-term neurobehavioral outcomes after cerebral ischemia in mice.

Preventive Cold Acclimation Increased the Therapeutic Effect of EPCs on Cerebral Ischemic Injury Reduction and Angiogenesis Promotion in Young Mice

To further determine whether EPC-mediated angiogenesis is involved in the protection of preventive cold acclimation against cerebral ischemic injury in mice, $1 \times 10^{6}$ bone marrow-derived EPCs from preventive cold-exposed and control mice were systemically administrated to mice just after cerebral ischemia, while control animals received an equal KARGER 
Fig. 3. Preventive cold acclimation before ischemia onset reduced mouse cortical atrophy and improved long-term neurobehavioral outcomes after cerebral ischemia in young mice. A. Surgical protocols: male young C57BL/6 mice (10-12 weeks of age) were randomly allocated to two groups ( $\mathrm{n}=19-20$ per group). The animals were exposed to the cold environment or maintained their usual lifestyle; 14 days later, they were subjected to permanent focal cerebral ischemia. Behavioral tests were performed at 7, 14, 21, and 28 days after cerebral ischemia and the cortical atrophy

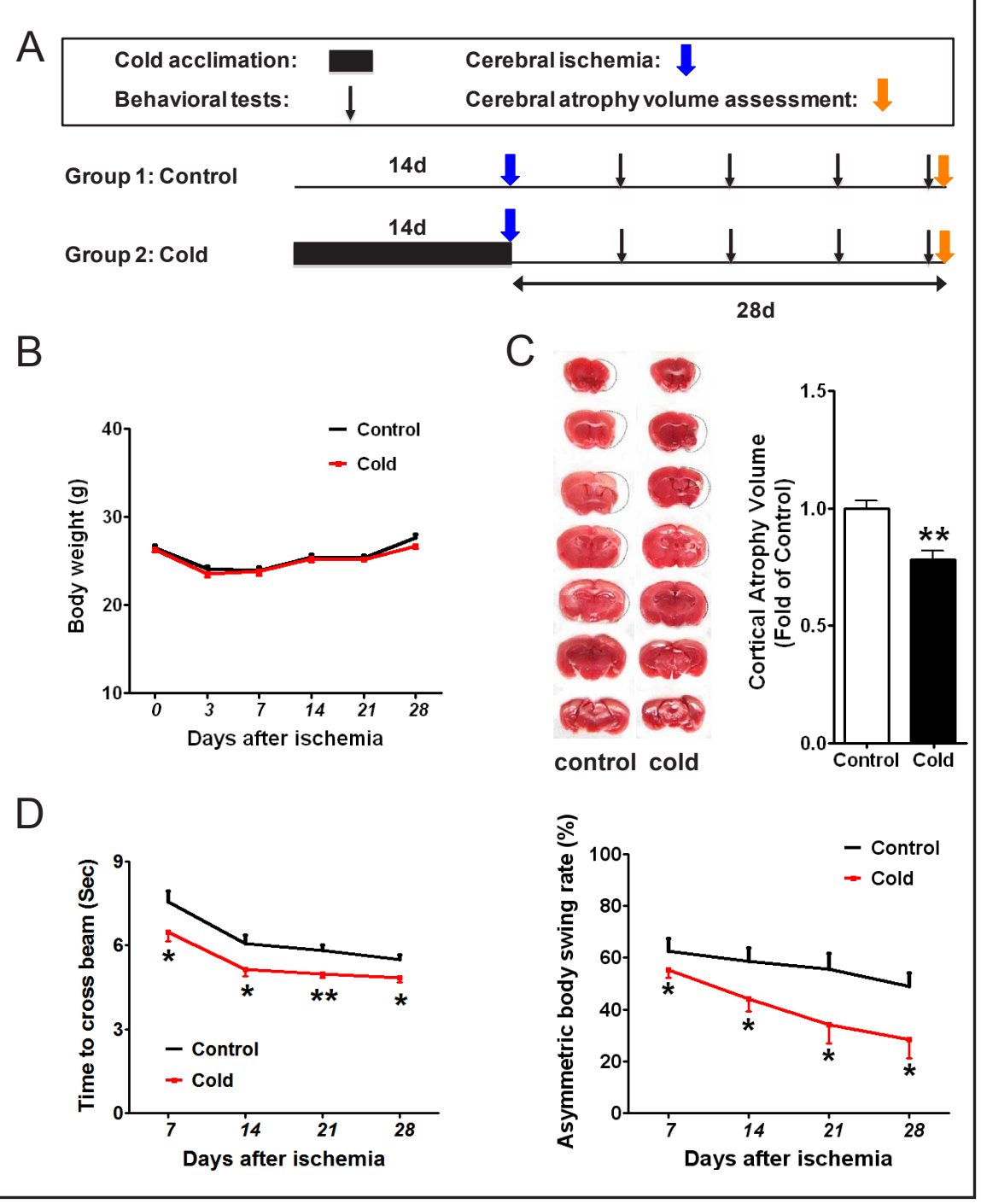
volumes were determined. B. Preventive cold acclimation showed no effect on body weights in mice. C. The 2,3,5-triphenyltetrazolium chloride (TTC) staining showed much less atrophy in the brains of the preventive cold-exposed mice than that of the control mice. The quantitative analysis showed that preventive cold acclimation significantly reduced the brain atrophy 28 days after cerebral ischemia compared with control. ${ }^{* *} \mathrm{P}<0.01$ vs. Control. D. Preventive cold acclimation improved neurobehavioral outcomes (including Beam Test and Body Asymmetry Test) in mice. ${ }^{*} \mathrm{P}<0.05$, ${ }^{* *} \mathrm{P}<0.01$ vs. Control. Control, control mice; Cold, preventive cold-exposed mice.

volume of vehicle (Fig. 4A). It was found that the infarct volumes were significantly reduced (EPC, $-24 \% ; P<0.01 v s$. vehicle; EPC-Cold, $-41 \%, P<0.01 v s$. vehicle) and the corresponding neurobehavioral outcomes were markedly improved in the two groups of EPC-treated mice compared with controls. However, the EPCs from preventive cold-exposed mice exerted a significantly higher therapeutic effect on cerebral ischemic injury than those from control mice $(P<0.01)$ (Fig. 4B).

Furthermore, the angiogenesis in the ischemic brain was assessed at 3 days after cerebral ischemia. Capillary density was significantly higher in the two groups of EPC-treated mice (EPC $+79 \%, P<0.01$ vs. vehicle; EPC-Cold, $+153 \%, P<0.01$ vs. vehicle). However, the EPCs from preventive cold-exposed mice exerted a significantly higher effect on angiogenesis promotion compared to those from control mice $(P<0.01)$ (Fig. 4C). 


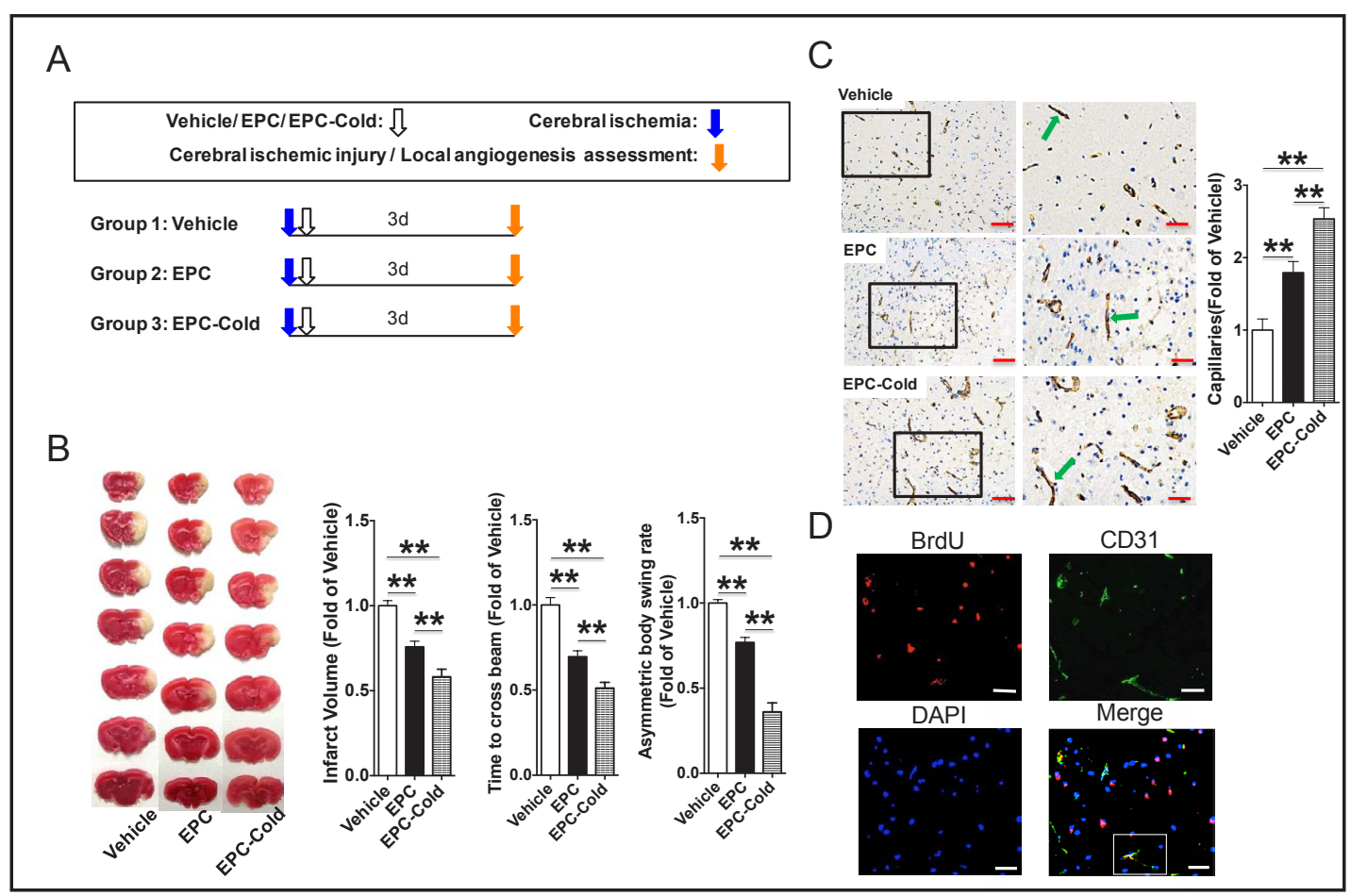

Fig. 4. Preventive cold acclimation increased the therapeutic effect of EPCs on cerebral ischemic injury reduction and angiogenesis promotion in young mice A, Surgical protocols: male young C57BL/6 mice (1012 weeks of age) were randomly allocated to three groups. Each group of animals received a single injection of vehicle, EPCs from control mice, or EPCs from cold-exposed mice just after cerebral ischemia. Behavioral tests were performed at 3 days after cerebral ischemia and the local angiogenesis in the ischemic brain and cerebral infarct volumes were determined. B. The representative images of 2,3,5-triphenyltetrazolium chloride (TTC) -stained brain sections, cerebral infarct volumes, and neurobehavioral outcomes (including Beam Test and Body Asymmetry Test) at 3 days after cerebral ischemia in mice. ${ }^{* *} \mathrm{P}<0.01 . \mathrm{n}=11-13$. C. CD31 immunostaining showing microvessels in the ischemic boundary area of ischemic brains. ${ }^{*} \mathrm{P}<0.01 . \mathrm{n}=6$. Scale bar: $100 \mu \mathrm{m}$ (left); $50 \mu \mathrm{m}$ (right). D. Typical photographs (taken from the ischemic boundary area) indicating that some BrdU-positive cells (red fluorescence) were incorporated into the CD31-positive vessels (green fluorescence) in the ischemic brain. The nucleus was counterstained with DAPI (blue fluorescence). A merged image is shown, and the white boxed region indicates CD31/BrdU double-positive cells. Scale bar: $50 \mu \mathrm{m}$. Values were normalized to Vehicle. Vehicle, mice treated with vehicle; EPC, mice treated with EPCs from control mice; EPC-Cold, mice treated with EPCs from cold-exposed mice.

To verify that BrdU-labeled EPCs were incorporated into the ischemic brains, the slides were stained with EC-specific marker CD31, followed by BrdU staining. As shown in Fig. 4D, some BrdU-positive cells (red fluorescence) were integrated into CD31-positive microvessels (green fluorescence) in the ischemic brains of mice subjected to EPC transplantation. Some BrdU-positive cells were found near the microvessels. In addition, EPCs from GFPtransgenic mice were also used for cell tracking in the ischemic brain to detect the in vivo EPC integration in mice. Intravenously delivered GFP-EPCs (green fluorescence) could home into ischemic brain at 3 days after injection in mice (Fig. 5). Previous studies have shown that transplanted EPCs can participate in angiogenesis within the ischemic brain and wounds [4, 6]. The present findings suggest that the transplanted EPCs could integrate into the ischemic brain and contribute to angiogenesis in mice.

These results indicate that the transplanted EPCs could home to ischemic brain, promote local angiogenesis and protect against cerebral ischemic injury in mice, and EPCs from preventive cold-exposed mice exerted a greater ability to promote angiogenesis and reduce cerebral ischemic injury than EPCs from control mice. 


\section{Cellular Physiology Cell Physiol Biochem 2018;45:175-191 \begin{tabular}{ll|l} 
and Biochemistry Published online: January 15, 2018 & $\begin{array}{l}\text { C } 2018 \text { The Author(s). Published by S. Karger AG, Basel } \\
\text { www.karger.com/cpb }\end{array}$ \\
\hline
\end{tabular} \\ Peng et al.: Cold Acclimation, EPCs and Stroke}

EPC Transplantation Improved Neurobehavioral Outcomes after 1 Day of Cerebral Ischemia in Young Mice

It has been demonstrated that an angiogenic reaction starts between 24 and 48 hours after cerebral infarction in mice [20]. To determine whether the transplanted EPCs possess non-angiogenic effects (e.g. paracrine effects) on cerebral ischemic injury in addition to their direct angiogenic effects, we assessed the neurobehavioral outcomes at 24 hours after cerebral ischemia in young mice (Fig. 6A). After 1 day of ischemia, the neurobehavioral outcomes were significantly improved in the two groups of EPC-treated mice compared to the control, while the EPCs from preventive cold-exposed mice exerted a significantly higher therapeutic effect on neurobehavioral outcomes than those from control mice $(P<0.01)$ (Fig. 6B).

These results indicate that transplanted EPCs might exert non-angiogenic effects on cerebral ischemic injury in addition to their direct angiogenic effects in mice.

Preventive Cold Acclimation Increased Therapeutic Effect of EPC-Conditioned Culture Medium on Cerebral Ischemic Injury in Young Mice

To study the paracrine effects of EPCs on cerebral ischemic injury, the conditioned media (CM) of mouse EPCs were collected and injected into mice via the tail vein (Fig. 6C). It was showed that the infarct volumes were significantly reduced (CM $-22 \%, P<0.01 v s$. Vehicle; CM-Cold $-37 \%, P<0.01$ vs. Vehicle) and the corresponding neurobehavioral outcomes were markedly improved in the two groups of CM-treated mice compared with the control. However, the CM of EPCs from preventive cold-exposed mice exerted a significantly higher therapeutic effect on cerebral ischemic injury than the CM of EPCs from control mice $(P<$ 0.05) (Fig. 6D).

To investigate the potential effect of cold acclimation on paracrine factors of EPCs in mice, the secreted VEGF, PDGF, and HGF levels in EPC-conditioned culture media were assessed (Fig. 7A). It was found that the secreted VEGF and PDGF levels were significantly increased in EPC-CM from cold-exposed mice compared with control (Fig. 7B and 7C). However, no significant difference in HGF levels in the EPC-CM was found between these two groups of mice (Fig. 7D).

Previous studies showed that EPC-conditioned medium can accelerate diabetic wound healing [4] and that the intravenous injection of EPC-conditioned media can enhance

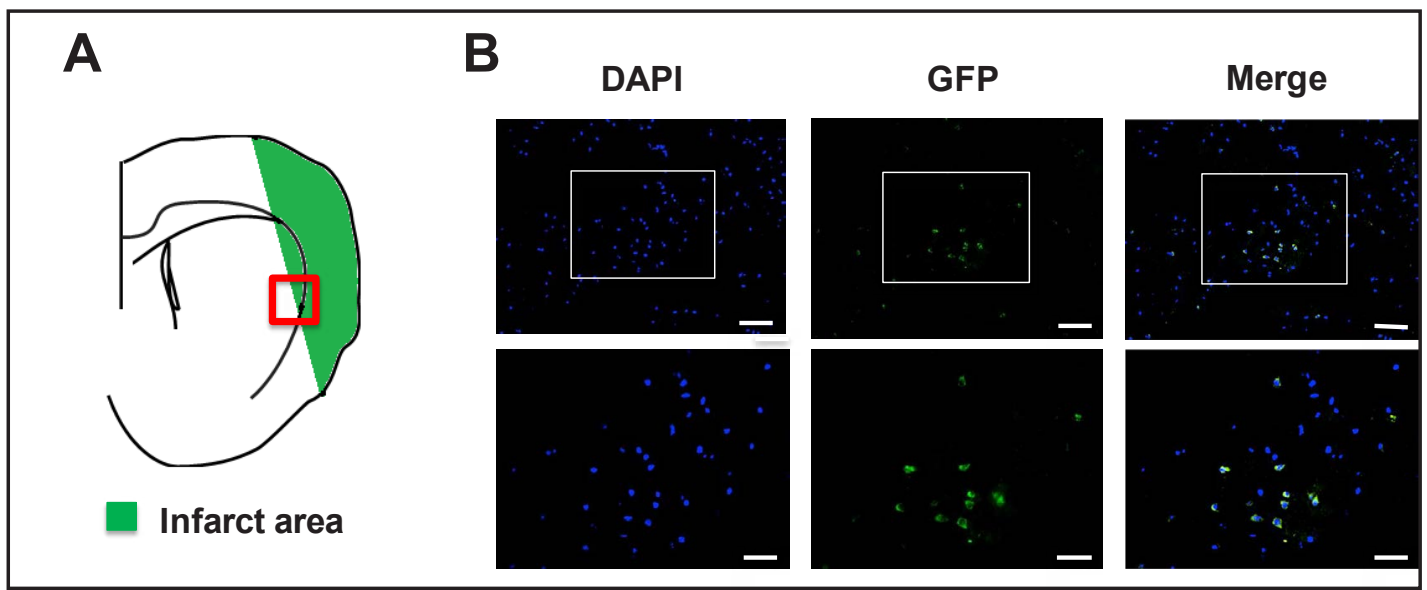

Fig. 5. Intravenously delivered EPCs home to ischemic brain in mice. A. The ischemic area and the ischemic boundary area of the ischemic brain. B. EPCs from GFP-transgenic mice (GFP-EPCs) were transplanted into the mice via the tail vein just after cerebral ischemia. Three days later, the mice were euthanized and the GFP-EPCs were detected in frozen ischemic brain sections. Photomicrographs (taken from the ischemic boundary area) show that some EPCs (green fluorescence) homed into the ischemic brain at 3 days after the injection. The cell nuclei were counterstained with DAPI (blue fluorescence). Scale bar: $100 \mu \mathrm{m}$ (up); $50 \mu \mathrm{m}$ (below). EPCs, endothelial progenitor cells; GFP, green fluorescent protein. 
Fig. 6. Preventive cold acclimation increased the therapeutic effect of EPC-conditioned culture medium on cerebral ischemic injury in young mice. A. Surgical protocols: male young C57BL/6 mice (10-12 weeks of age) were randomly allocated to three groups. Each group of animals received a single injection of vehicle, EPCs from control mice, or EPCs from cold-exposed mice just after cerebral ischemia. Behavioral tests were performed at 1 day after cerebral ischemia. B. EPC transplantation improved neurobehavioral outcomes (including Beam Test and Body Asymmetry Test) at 1 day after cerebral ischemia. Values were normalized to Vehicle. ${ }^{* *} \mathrm{P}<0.01 . \mathrm{n}=11-13$. Vehicle-1d, mice treated with vehicle; EPC-1d, mice treated with EPCs from control mice; EPC-Cold-1d, mice treated with EPCs from cold-exposed mice. C. Surgical protocols: male young C57BL/6 mice (10-12 weeks of age) were randomly allocated to three groups. Each group of animals received a single injection of vehicle, $\mathrm{CM}$ from control mice, or CM from cold-exposed mice just after cerebral ischemia. Behavioral tests were performed at 1 day after cerebral ischemia and the cerebral infarct volumes were determined. D. Representative images of TTC-stained brain sections, cerebral infarct volumes, and neurobehavioral outcomes (including Beam Test and Body Asymmetry Test) at 1 day after cerebral ischemia. Values were normalized to Vehicle. ${ }^{* *} \mathrm{P}<0.01 . \mathrm{n}=10-12$. CM, conditioned culture medium; Vehicle, mice treated with vehicle; $\mathrm{CM}$, mice treated with $\mathrm{CM}$ from control mice; CM-Cold, mice treated with CM from cold-exposed mice; TTC, 2,3,5-triphenyltetrazolium chloride.

neurorepair responses after cerebral ischemia in mice [19]. Our present findings suggest that EPCs might exert paracrine effects on cerebral ischemic injury in addition to their direct angiogenic effects, while preventive cold acclimation increased the therapeutic effect of EPCconditioned medium on cerebral ischemic injury in mice.

Preventive Cold Acclimation before Ischemia Onset Increased EPC Function, Promoted Local Angiogenesis in the Ischemic Brain, and Protected Against Cerebral Ischemic Injury in Aged Mice

Next, aged mice were employed to investigate whether the effects of preventive cold acclimation observed in young healthy mice could be reproduced in a model of stroke risk factors. Compared with young healthy mice, BM-EPC functions (including migration, adhesion, and tube formation functions) were significantly reduced in aged mice, which was rescued by a 14-day preventive cold acclimation period ( $P<0.01$ vs. Old) (Fig. 8). 
Fig. 7. Effects of preventive cold acclimation on secreted VEGF, PDGF, and HGF levels in EPCconditioned culture medium in mice. A. Experimental protocols: male young C57BL/6 mice (10-12 weeks of age) were randomly allocated to two groups. Animals were exposed to the cold environment or maintained their usual lifestyle; 14 days later, the EPCs were isolated and cultured and the EPCconditioned culture medium was collected and concentrated. Secreted VEGF, PDGF, and HGF levels in the CM were assessed by western blot analysis. B. Secreted VEGF levels in the CM $(n=3)$. C. Secreted PDGF levels in the CM $(n=3)$. D. Secreted HGF levels in the CM ( $\mathrm{n}=$ 3 ). Values were normalized to control. ${ }^{*} \mathrm{P}<0.05$, ${ }^{* *} \mathrm{P}<0.01$ vs. Control. EPCs, endothelial progenitor cells; $\mathrm{CM}$, conditioned culture medium; Control, control mice; Cold, preventive cold-exposed mice; VEGF, vascular endothelial growth factor; PDGF, platelet-derived growth factor; HGF, hepatocyte growth factor.

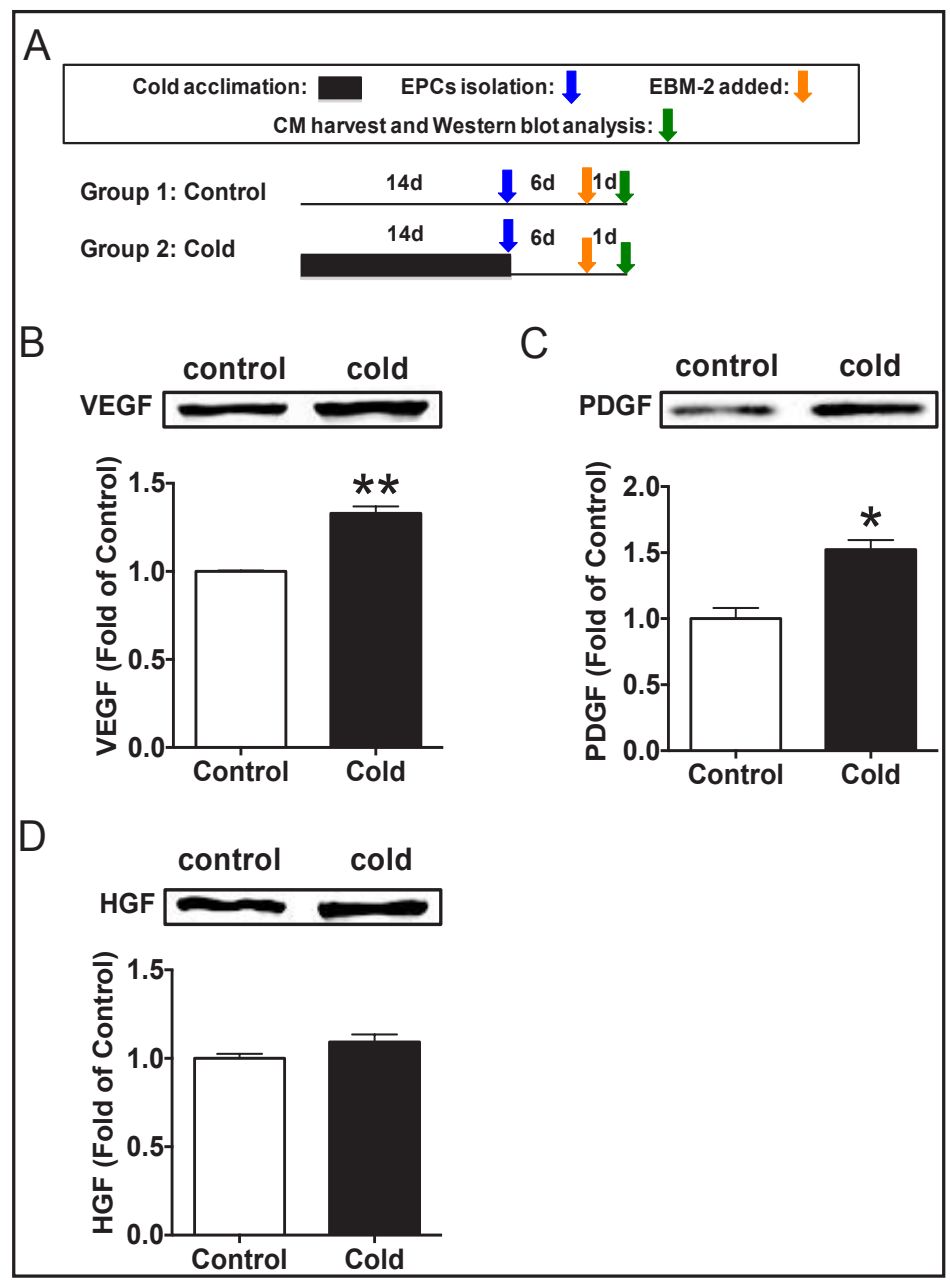

We then sought to investigate whether the promotion of EPC functions by preventive cold acclimation before ischemia onset would lead to a preventive action on the cerebral ischemic injury reduction in aged mice. After the 14-day cold acclimation period, aged mice were subjected to cerebral ischemia and we determined the local angiogenesis in the ischemic brain and cerebral ischemic injury at 3 days after cerebral ischemia (Fig. 9A). Compared with young healthy mice, the capillary density was significantly decreased in aged mice, which was reversed in preventive cold-exposed aged mice $(+47 \%, P<0.01$ vs. Old) (Fig. 9B). Moreover, we found that, compared with young healthy mice, the infarct volumes were significantly increased and the corresponding neurobehavioral outcomes were markedly impaired in aged mice, a phenomenon that was reversed in preventive cold-exposed aged mice $(P<0.01$ vs. Old) (Fig. 9C). These results indicate that preventive cold acclimation before ischemia onset could increase EPC functions, promote local angiogenesis in the ischemic brain, and protect against cerebral ischemic injury in aged mice.

\section{Discussion}

This is the first study to show that preventive cold acclimation before ischemia onset could promote the reparative function of EPCs in the ischemic murine brain.

EPCs play an important role in tissue repair and regeneration in the ischemic brain [46]. Here we found, for the first time, that preventive cold acclimation before ischemia onset could increase EPC function, promote angiogenesis in the ischemic brain, reduce the cerebral 


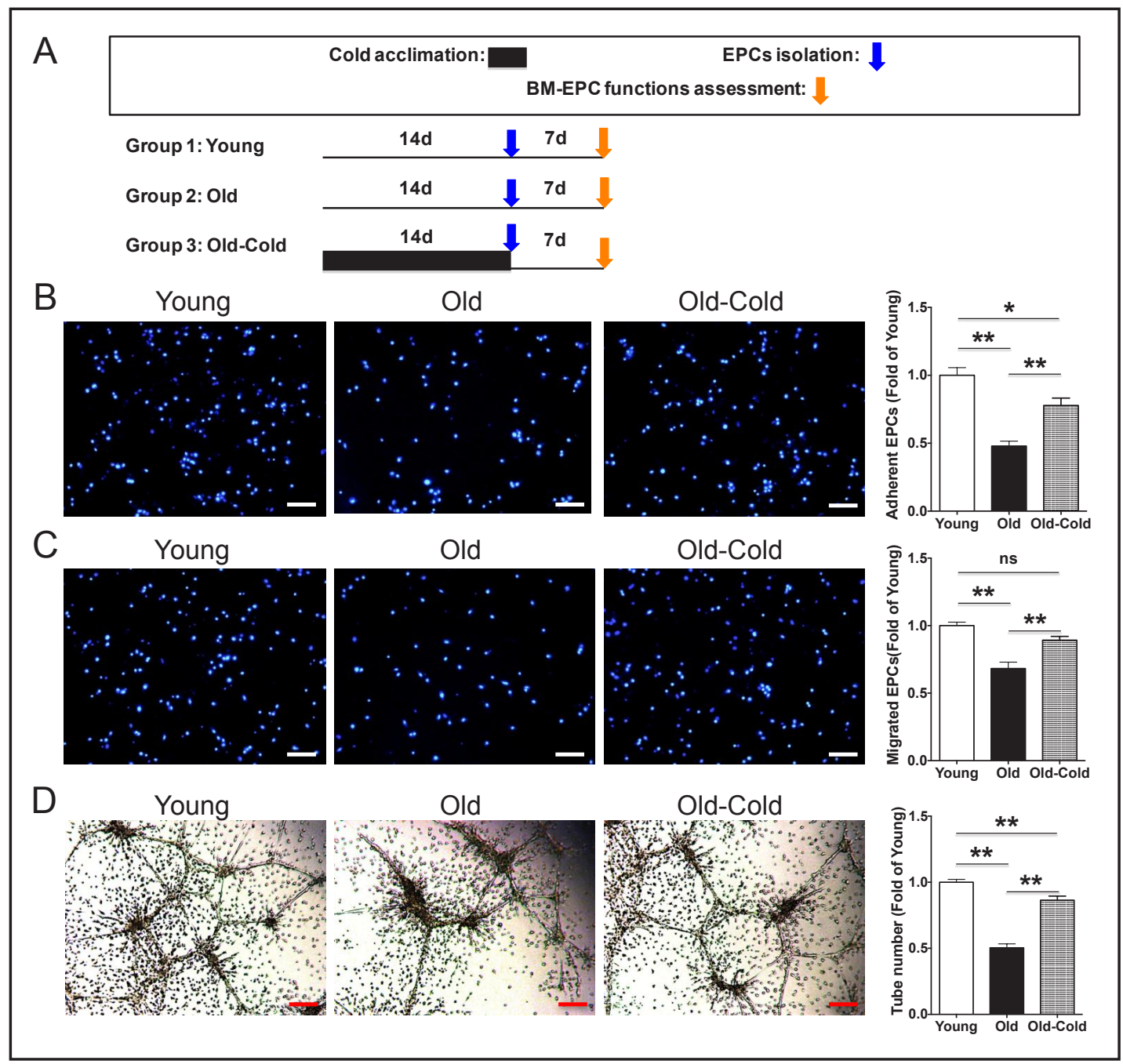

Fig. 8. Preventive cold acclimation increased EPC function in aged mice. A. Experimental protocols: male aged C57BL/6 mice (52-55 weeks of age) were randomly allocated to two groups, and the animals were exposed to the cold environment or maintained their usual lifestyle. A group of young male C57BL/6 mice (10-12 weeks of age) comprised the control group. After the 14-day cold acclimation period, BM-EPCs were isolated, cultured, and examined. B. Adhesion assay of BM-EPCs. C. Migration assay of BM-EPCs. D. Tube formation assay of BM-EPCs. Values were normalized to Young. ${ }^{*} \mathrm{P}<0.05$, ${ }^{* *} \mathrm{P}<0.01 . \mathrm{n}=8-10$. Scale bar: 100 $\mu \mathrm{m}$. EPC, endothelial progenitor cells; BM-EPCs, bone marrow-derived EPCs; Young, young mice; Old, aged mice; Old-Cold, preventive cold-exposed aged mice.

ischemic injury in both young and aged mice, and improve long-term neurobehavioral outcomes in young mice. Furthermore, we found that the transplantation of EPCs from coldexposed mice showed a higher therapeutic effect on cerebral ischemic injury reduction and local angiogenesis promotion than those from control mice, while the EPCs from the donor animals could integrate into the recipient ischemic brain. In addition, EPC-conditioned medium containing growth factors (including PDGF, VEGF, and HGF) can accelerate diabetic wound healing, while the intravenous injection of EPC-conditioned medium after 1 day of cerebral ischemia can promote angiogenesis and improve the neurological outcomes after cerebral ischemia in mice $[4,19]$. Consistent with these results, the present findings suggested that EPCs might exert paracrine effects on cerebral ischemic injury reduction in addition to their direct angiogenic effects in mice, which could be improved by the preventive cold acclimation. Therefore, the promotion of both EPC-mediated ischemic brain angiogenesis

\section{KARGER}




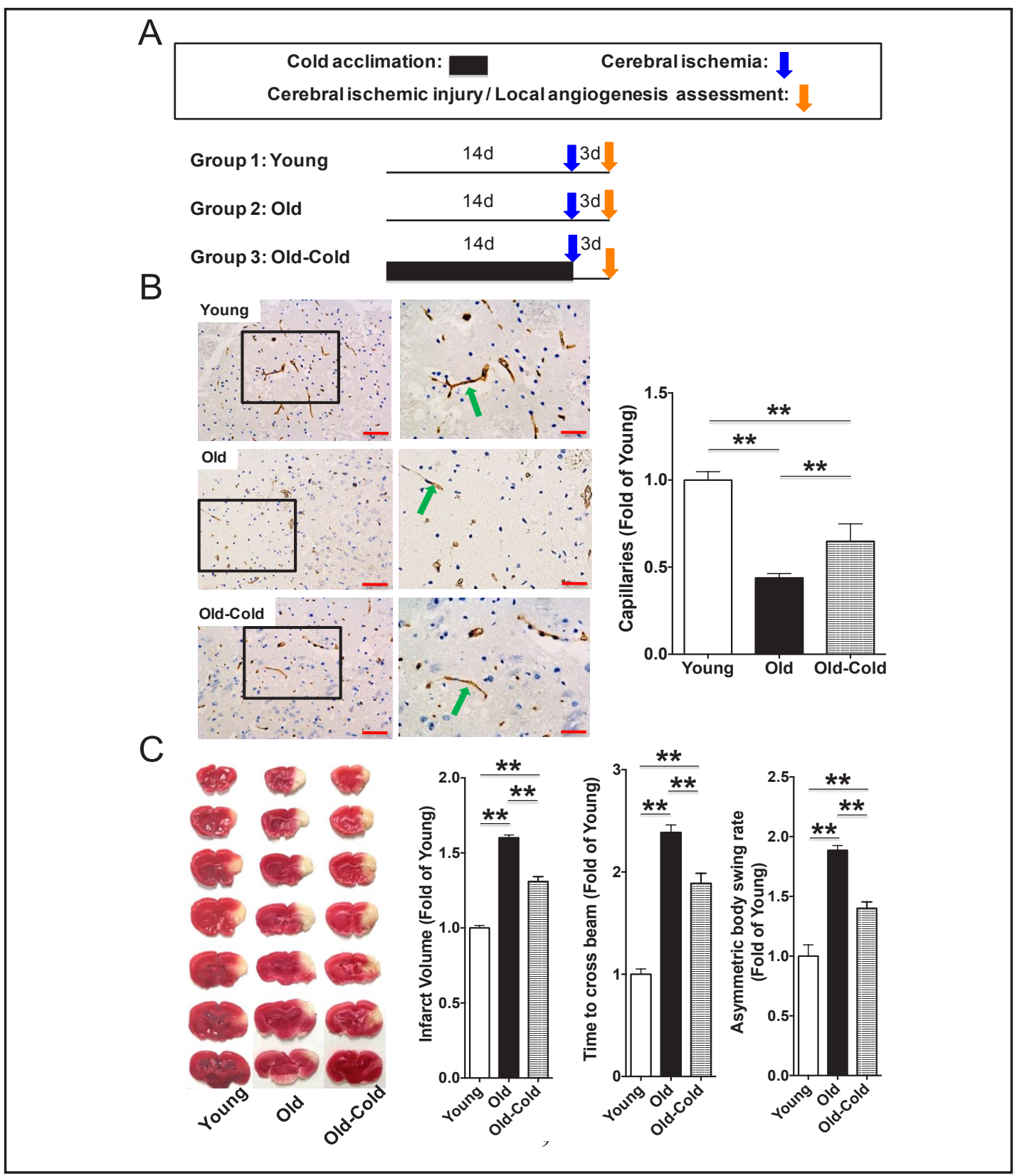

Fig. 9. Preventive cold acclimation before ischemia onset promoted angiogenesis in the ischemic brain and protected against cerebral ischemic injury in aged mice. A. Surgical protocols: male aged C57BL/6 mice (52-55 weeks of age) were randomly allocated to two groups, and the animals were exposed to cold environment or maintained their usual lifestyle. A group of young male C57BL/6 mice (10-12 weeks of age) comprised the control group. After the 14-day cold acclimation period, the mice were subjected to permanent focal cerebral ischemia. Behavioral tests were performed at 3 days after cerebral ischemia and the local angiogenesis and infarct volume of the ischemic brain were determined. B. Preventive cold acclimation promoted local angiogenesis in the ischemic boundary area of the ischemic brains in aged mice. The bar graph shows that the number of microvessels in the preventive cold-exposed aged mice was significantly increased compared with the aged mice. Values were normalized to Young. ${ }^{* *} \mathrm{P}<0.01 . \mathrm{n}=12$. Scale bar: $100 \mu \mathrm{m}$ (left); $50 \mu \mathrm{m}$ (right). C. Representative images of TTC-stained brain slices, cerebral infarct volumes, and neurobehavioral outcomes (including Beam Test and Body Asymmetry Test). Values were normalized to Young. ${ }^{* *} \mathrm{P}<0.01 . \mathrm{n}=9-10$. Young, young mice; Old, aged mice; Old-Cold, preventive coldexposed aged mice; TTC, 2,3,5-triphenyltetrazolium chloride.

\section{KARGER}


and EPC paracrine effects, as observed in the present study, may partly contribute to the protection of preventive cold acclimation against cerebral ischemic injury in mice. Other possible mechanisms of this response remain to be investigated in further studies.

In addition, because EPCs have been implicated in vascular repair and revascularization in various ischemic organs other than brain tissue [4-6], the preventive cold acclimation before ischemia onset might serve as a strategy to prevent other ischemic diseases except stroke, such as myocardial and limbic ischemic injury, which remains to be tested in further studies.

Furthermore, preventive cold acclimation before ischemia onset possesses some obvious advantages over the aforementioned stroke prevention measures [9]: 1) it is an easy, practical, and economic preventive approach; and 2) it might be a broad-spectrum preventive approach applicable to the patients with different risk factors for stroke, such as aging and hypertension.

eNOS and MnSOD have been shown to critically regulate EPC function [4, 21]. Studies have also demonstrated that increased $\mathrm{O}_{2}$ - production induced TSP-1 expression in cultured endothelial cells and EPCs, and TSP- 1 has been proposed as a key inhibitor of endothelial cell and EPC function [11, 22]. Thus, the increased eNOS and MnSOD levels and decreased TSP-1 and intracellular $\mathrm{O}_{2}^{-}$levels observed in the present study might represent a portion of the mechanisms underlying the ability of preventive cold acclimation to improve EPC function.

Persistent severe cold exposure (adapted at $18^{\circ} \mathrm{C}$ for 1 week, followed by exposure to $4^{\circ} \mathrm{C}$ for another 3 or 7 weeks) promotes atherosclerotic plaque growth and instability via UCP1-dependent lipolysis in mice [23]. However, the intermittent and repeated mild cold exposure used in the present study seemed not to have these adverse effects.

\section{Conclusion}

In summary, preventive cold acclimation before ischemia onset protected against cerebral ischemic injury and improved long-term neurobehavioral outcomes in mice, at least in part, by promoting EPC-mediated angiogenesis in the ischemic brain and improving the EPCs' paracrine effects. The finding implies that a variable indoor environment with frequent cold exposure before ischemia onset might be an acceptable and economic manner of stroke prevention and might be beneficial to individuals such as the elderly who are at relatively high risk for ischemic diseases.

\section{Acknowledgements}

This work was supported by the National Key Basic Research Program of China (973 Program; 2014CB542403), the National Natural Science Foundation of China (81370253, 81170115 and 81603097).

\section{Disclosure Statement}

None.

\section{References}

1 Yoneshiro T, Aita S, Matsushita M, Kayahara T, Kameya T, Kawai Y, Iwanaga T, Saito M: Recruited brown adipose tissue as an antiobesity agent in humans. J Clin Invest 2013;123:3404-3408.

-2 van der Lans AA, Hoeks J, Brans B, Vijgen GH, Visser MG, Vosselman MJ, Hansen J, Jorgensen JA, Wu J, Mottaghy FM, Schrauwen P, van Marken Lichtenbelt WD: Cold acclimation recruits human brown fat and increases nonshivering thermogenesis. J Clin Invest 2013;123:3395-3403.

-3 Jensen MK, Bertoia ML, Cahill LE, Agarwal I, Rimm EB, Mukamal KJ: Novel metabolic biomarkers of cardiovascular disease. Nat Rev Endocrinol 2014;10:659-672.

4 Marrotte EJ, Chen DD, Hakim JS, Chen AF: Manganese superoxide dismutase expression in endothelial progenitor cells accelerates wound healing in diabetic mice. J Clin Invest 2010;120:4207-4219. 


\section{Cellular Physiology Cell Physiol Biochem 2018;45:175-191 \begin{tabular}{l|l|l} 
and Biochemistry $10.1159 / 000486356$ & $\begin{array}{l}\text { C) } 2018 \text { The Author(s). Published by S. Karger AG, Basel } \\
\text { www.karger.com/cpb }\end{array}$ \\
\hline
\end{tabular}}

Peng et al.: Cold Acclimation, EPCs and Stroke

5 Zhao YH, Yuan B, Chen J, Feng DH, Zhao B, Qin C, Chen YF: Endothelial progenitor cells: therapeutic perspective for ischemic stroke. CNS Neurosci Ther 2013;19:67-75.

-6 Fan Y, Shen F, Frenzel T, Zhu W, Ye J, Liu J, Chen Y, Su H, Young WL, Yang GY: Endothelial progenitor cell transplantation improves long-term stroke outcome in mice. Ann Neurol 2010;67:488-497.

-7 Ferrell AS, Britz GW: Developments on the horizon in the treatment of neurovascular problems. Surg Neurol Int 2013;4:S31-37.

-8 Glover LE, Tajiri N, Weinbren NL, Ishikawa H, Shinozuka K, Kaneko Y, Watterson DM, Borlongan CV: A Stepup Approach for Cell Therapy in Stroke: Translational Hurdles of Bone Marrow-Derived Stem Cells. Transl Stroke Res 2012;3:90-98.

-9 Meschia JF, Bushnell C, Boden-Albala B, Braun LT, Bravata DM, Chaturvedi S, Creager MA, Eckel RH, Elkind MS, Fornage M, Goldstein LB, Greenberg SM, Horvath SE, Iadecola C, Jauch EC, Moore WS, Wilson JA, American Heart Association Stroke C, Council on C, Stroke N, Council on Clinical C, Council on Functional G, Translational B, Council on H: Guidelines for the primary prevention of stroke: a statement for healthcare professionals from the American Heart Association/American Stroke Association. Stroke 2014;45:37543832.

10 Dumitrascu OM, Lamb J, Lyden PD: Still cooling after all these years: Meta-analysis of pre-clinical trials of therapeutic hypothermia for acute ischemic stroke. J Cereb Blood Flow Metab 2016;36:1157-1164.

11 Xie HH, Zhou S, Chen DD, Channon KM, Su DF, Chen AF: GTP cyclohydrolase I/BH4 pathway protects EPCs via suppressing oxidative stress and thrombospondin-1 in salt-sensitive hypertension. Hypertension 2010;56:1137-1144.

12 Dong XH, Sun X, Jiang GJ, Chen AF, Xie HH: Dietary intake of sugar substitutes aggravates cerebral ischemic injury and impairs endothelial progenitor cells in mice. Stroke 2015;46:1714-1718.

-13 Xin B, Liu CL, Yang H, Peng C, Dong XH, Zhang C, Chen AF, Xie HH: Prolonged Fasting Improves Endothelial Progenitor Cell-Mediated Ischemic Angiogenesis in Mice. Cell Physiol Biochem 2016;40:693-706.

14 Wang LP, Jiang Y, Yang H, Peng C, Zhang C, Tao X, Xie HH: Combination Therapy of Nifedipine and Sulphonylureas Exhibits a Mutual Antagonistic Effect on the Endothelial Cell Dysfunction Induced by Hyperglycemia Linked to Vascular Disease. Cell Physiol Biochem 2016;38:2337-2347.

-15 Zhu W, Fan Y, Frenzel T, Gasmi M, Bartus RT, Young WL, Yang GY, Chen Y: Insulin growth factor-1 gene transfer enhances neurovascular remodeling and improves long-term stroke outcome in mice. Stroke 2008;39:1254-1261.

16 Li Y, Jiang N, Powers C, Chopp M: Neuronal damage and plasticity identified by microtubule-associated protein 2, growth-associated protein 43 , and cyclin D1 immunoreactivity after focal cerebral ischemia in rats. Stroke 1998;29:1972-1980; discussion 1980-1971.

17 Chen J, Zhang C, Jiang H, Li Y, Zhang L, Robin A, Katakowski M, Lu M, Chopp M: Atorvastatin induction of VEGF and BDNF promotes brain plasticity after stroke in mice. J Cereb Blood Flow Metab 2005;25:281290.

18 Zhang ZG, Zhang L, Jiang Q, Chopp M: Bone marrow-derived endothelial progenitor cells participate in cerebral neovascularization after focal cerebral ischemia in the adult mouse. Circ Res 2002;90:284-288.

19 Rosell A, Morancho A, Navarro-Sobrino M, Martinez-Saez E, Hernandez-Guillamon M, Lope-Piedrafita S, Barcelo V, Borras F, Penalba A, Garcia-Bonilla L, Montaner J: Factors secreted by endothelial progenitor cells enhance neurorepair responses after cerebral ischemia in mice. PLoS One 2013;8:e73244.

20 Marti HJ, Bernaudin M, Bellail A, Schoch H, Euler M, Petit E, Risau W: Hypoxia-induced vascular endothelial growth factor expression precedes neovascularization after cerebral ischemia. Am J Pathol 2000;156:965976.

21 Aicher A, Heeschen C, Mildner-Rihm C, Urbich C, Ihling C, Technau-Ihling K, Zeiher AM, Dimmeler S: Essential role of endothelial nitric oxide synthase for mobilization of stem and progenitor cells. Nat Med 2003;9:1370-1376.

22 Ii M, Takenaka H, Asai J, Ibusuki K, Mizukami Y, Maruyama K, Yoon YS, Wecker A, Luedemann C, Eaton E, Silver M, Thorne T, Losordo DW: Endothelial progenitor thrombospondin-1 mediates diabetes-induced delay in reendothelialization following arterial injury. Circ Res 2006;98:697-704.

23 Dong M, Yang X, Lim S, Cao Z, Honek J, Lu H, Zhang C, Seki T, Hosaka K, Wahlberg E, Yang J, Zhang L, Lanne T, Sun B, Li X, Liu Y, Zhang Y, Cao Y: Cold exposure promotes atherosclerotic plaque growth and instability via UCP1-dependent lipolysis. Cell Metab 2013;18:118-129. 